\title{
New Magnetic Anomaly Map of the East Asia with Some Preliminary Tectonic Interpretations
}

\author{
Wen-Bin Doo *, Shu-Kun Hsu, and Leo Armada \\ Department of Earth Sciences, National Central University, Jhongli, Taiwan
}

Received 17 September 2013, revised 6 April 2014, accepted 19 August 2014

\begin{abstract}
Magnetic data provides basic information for geological and geophysical interpretation. In this study we compile recently collected (57 cruises survey) and old (published and open access) magnetic data. This compilation includes land, marine and aeromagnetic data acquired in the East Asia region. The newly acquired magnetic data are mainly concentrated mainly in the South China Sea (SCS) (especially in the northern continental shelf), the northwestern part of the West Philippine Basin (WPB), and the East China Sea. The updated magnetic dataset is gridded with a spacing of one arc-minute. The new magnetic map provides new insights into the tectonic setting of East Asia. Analysis of the compiled data reveals several regional anomaly patterns: (1) the NE-SW trending high positive magnetic anomaly zone extending from southwest Taiwan to the area about $114.5^{\circ} \mathrm{E}$ and $22^{\circ} \mathrm{N}$ is pronounced; but it is less continuous southwest of the Penghu islands. In addition, the orientation of this high linear magnetic zone changes slightly in $118.5^{\circ} \mathrm{E}, 22.5^{\circ} \mathrm{N}$ from $\mathrm{N} 60^{\circ} \mathrm{E}-\mathrm{N} 50^{\circ} \mathrm{E}$. (2) Between the Gagua Ridge (GR) and the Luzon-Okinawa Fracture Zone (LOFZ) the marine magnetic stripes of the WPB exhibit a NW-SE orientation. This suggests that the seafloor spreading could be related to the first stage of the WPB east of the LOFZ. (3) The Urdaneta and Amami plateaus are associated with high magnetization zones. These high magnetization zones extend northwestward and are subducting beneath the Ryukyu Trench.
\end{abstract}

Key words: Magnetic anomaly map, East Asia, West Philippine Basin, South China Sea, Tectonics

Citation: Doo, W. B., S. K. Hsu, and L. Armada, 2015: New magnetic anomaly map of the East Asia with some preliminary tectonic interpretations. Terr. Atmos. Ocean. Sci., 26, 73-81, doi: 10.3319/TAO.2014.08.19.07(GRT)

\section{INTRODUCTION}

Magnetic data generally provide fundamental information on the structural characteristic and the volcanic nature of underlying sources. Hsu et al. (1998) compiled shipboard magnetic data offshore Taiwan and aeromagnetic data off western Taiwan and presented a general description of the tectonics around Taiwan. However, because of some poor data density attributed to the sparseness of existing data sources or the lack of ship tracks in some areas, several magnetic features were still not clear. Hsu et al. (2004) improved the magnetic data coverage in the northernmost South China Sea (SCS) by adding several N-S direction magnetic surveys and confirmed the existence of several ENE-WSW trending magnetic lineations that were interpreted as magnetic polarity reversals. The magnetic polarity reversals designate the initial age of the SCS opening in

\footnotetext{
* Corresponding author

E-mail:wenbindoo@gmail.com
}

magnetic isochron C17 (Hsu et al. 2004).

Geological Survey of Japan and Coordinating Committee for Coastal and Offshore Geoscience Programs in East and Southeast Asia (CCOP 1996) collected available shipboard magnetic data as well as part of an on land data set and compiled a data set of one arc minute by one arc minute resolution in the East and Southeast Asia area. Over the oceans, much of the marine magnetic data are stored in the Geophysical Data System (GEODAS) (Metzger and Campagnoli 2007) of the U.S. National Geophysical Data Center (NGDC). However, the quality of this dataset has not been checked at a global scale until the recent study of Chandler and Wessel (2008). Quesnel et al. (2009) used the GEODAS DVD Version 5.0.10. This global dataset consists of 2411 cruises with acquisition times spanning from 1953 - 2003. The authors corrected each magnetic measurement stored in the GEODAS, by subtracting the reliable core and external field contributions and also by checking the anomaly value 
track by track. Their work improved the quality of the global marine magnetic dataset.

As described above, the dataset compiled by Hsu et al. $(1998,2004)$ focused only on the Taiwan-Luzon region. Although the coverage of the two global datasets (CCOP 1996; Quesnel et al. 2009) are good, some areas still lack ship track lines and the low data density in these areas cannot reflect the local structural characteristics. For example, in the northwestern corner of the West Philippine Basin (WPB), due to poor data density in the past, the correlation between the Central Basin Spreading Center and the west side of the Luzon-Okinawa Fracture Zone (LOFZ) is still controversial. In this study we compiled the newly acquired and available magnetic data in the East Asia area. The newly acquired magnetic data are mainly concentrated in the SCS (especially in the northern continental shelf), the northwestern part of the WPB and the East China Sea. We anticipate that the improved magnetic data will provide new insights into the tectonic features and increase resolution in the local area.

\section{DATA PROCESSING AND COMPILATION}

The dataset of Hsu et al. (2004) covers a large area around the Taiwan region (Fig. 1). Moreover, analysis of internal cross-over error for the Hsu et al. (2004) dataset gives a mean error and standard deviation of 0.02 and $1.02 \mathrm{nT}$, respectively (Fig. 2). The result shows good data quality. Therefore this dataset becomes a suitable reference for the adjustment of other magnetic data. The analysis of cross-over errors will be used to adjust the datum level of each cruise.

\subsection{Newly Acquired Data}

From 2004 - 2010, we collected data from 57 magnetic cruises using different research vessels. Most of these cruises were conducted for the continental shelf survey project from 2006 - 2010. The main purpose of this project is to investigate the potential natural resources and the extension of the exclusive economic zone offshore Taiwan. The other cruises were conducted for tectonics research in the Taiwan region. Information on these surveys is shown in Table 1. Geomagnetic total field data were collected using a surfacetowed proton precession magnetometer. The instrument was generally towed $180 \mathrm{~m}$ (depends on the size of the ship) behind the ship. When Global Positioning Systems (GPS) became available in the early 1990 s, errors on positioning were reduced to less than $100 \mathrm{~m}$ and since 1 May 2000, to less than $20 \mathrm{~m}$ worldwide. GPS navigation was used during all new cruises. Therefore, the positioning accuracy of the research vessel is good. According to the ship's heading, taking into account the cable length we can process the positioning correction (magnetometer towing shift).

In order to modify and remove erroneous data the second step of the processing is a thorough checking the data, track by track using the software of Chang et al. (2011). The main advantage of this software is that it can check the geomagnetic value variation from a data distribution map as well as from the selected profile and delete the wrong data directly. After that, the geomagnetic data were reduced to magnetic anomalies by subtracting the reference field given by International Geomagnetic Reference Field (IGRF) model. Geomagnetic data acquired before year 2010 were reduced to magnetic anomalies by subtracting the total field given by the IGRF11 model (Finlay et al. 2010). Due to few permanent observatories inland on Taiwan and the

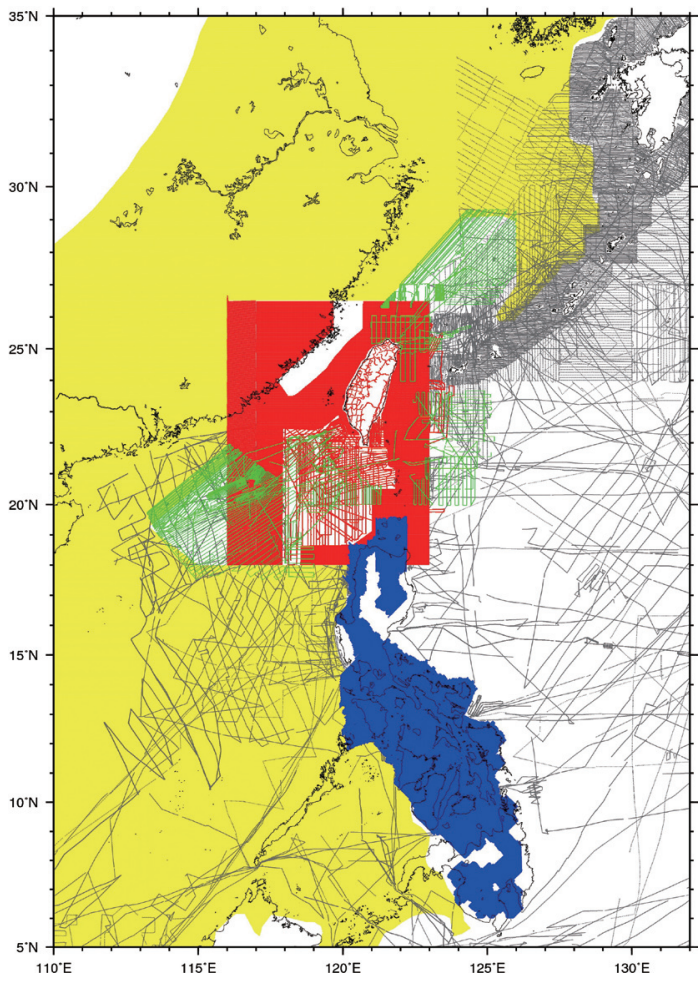

Fig. 1. Distribution of magnetic data. Red points indicate Hsu et al (2004) dataset; green points indicate new collected data from 2004 - 2010; blue area indicates Philippine aeromagnetic data (Bureau of Energy Development 1985); gray points indicate Quesnel et al. (2009) dataset; yellow area indicates CCOP (1996) dataset.

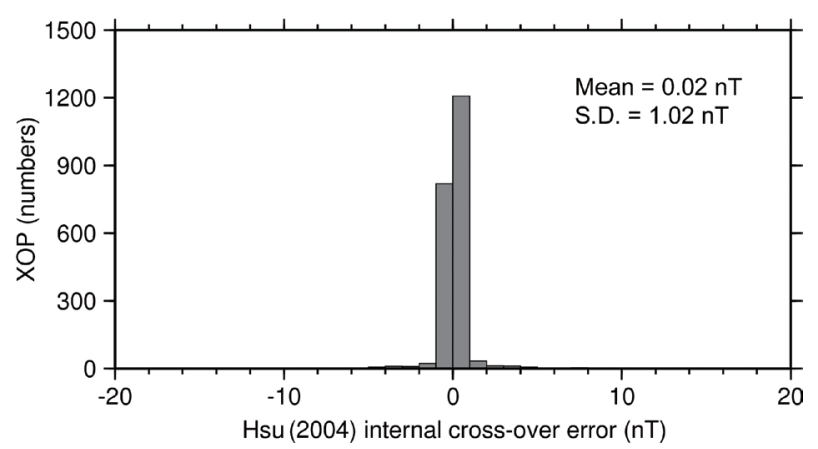

Fig. 2. Internal cross-over errors of the Hsu et al. (2004) dataset. 
Table 1. Cruise names and years of newly collected magnetic data used in the compilation.

\begin{tabular}{|c|c|c|}
\hline & Time & Cruise name \\
\hline \multirow{7}{*}{$\begin{array}{l}\text { Newly } \\
\text { collected }\end{array}$} & 2004 & OR1-730, OR1-738, OR1-740, OR1-741 \\
\hline & 2005 & OR1-754, OR1-759, OR1-764, OR1-767, OR1-769, OR3-1049 \\
\hline & 2006 & OR1-766, TK060819, TK060824, TK060907, TK060918, TK061001, TK061009, TK061020 \\
\hline & 2007 & TK070329, TK070411, TK070423, TK070507, TK070627, TK070713, TK070723, TK070823, TK070903, TK070917 \\
\hline & 2008 & $\begin{array}{l}\text { TK080305, TK080323, TK080402, TK080416, TK080430, TK080519, TK080602, TK080617, TK080807, } \\
\text { FR1-081028, OR1-876, OR2-1569, OR2-1579 }\end{array}$ \\
\hline & 2009 & TK090513, TK090527, TK090610, TK090819, TK090916, TK091014, FR1-091104, FR1-091123 \\
\hline & 2010 & OR2-100318, YY2-100411, OR2-100609, OR2-100712, TK100524, TK100607, FR1-100504, FR1-100617 \\
\hline
\end{tabular}

great distances between survey areas and permanent recording stations, only few cruise data were subjected to diurnal variation correction.

Due to different data collection times, instrument drift, ocean currents, all effects could result in the datum level error between different cruises at the same location. The method of Hsu (1995) was used in this study to adjust the datum level error for each cruise. This method can find all of the cross-over point locations and the different values in each location. Using this method we can adjust the levels of the different datasets so that all of the cross-over errors will become zeros after adjustment. We have compiled the newly acquired data and the dataset of Hsu et al. (2004) data set. For convenience, we divided recently collected magnetic data into three parts depending on the data distribution (northeast, east and southwest part of Taiwan) (green lines in Fig. 1). The mean error and standard deviation of the newly collected data from the NE, E, and SW Taiwan relative to Hsu et al. (2004) are 15.19 and 27.22, 7.96 and 22.04, and -9.07 and $16.00 \mathrm{nT}$, respectively (Fig. 3).

\subsection{Other Datasets}

In order to extend the data coverage and fill in magnetic data gaps, our new collected data, data from CCOP (1996) (yellow area in Fig. 1), Quesnel et al. (2009) (gray lines in Fig. 1) global ocean magnetic dataset and the aeromagnetic survey in the Philippines (collected in 1983) (Bureau of Energy Development 1985) (blue area in Fig. 1) were used. All magnetic data used in this study are shown in Fig. 1. Blank regions indicate no data coverage areas. The CCOP (1996) and Quesnel et al. (2009) data sets were previously described. The Philippine high-sensitivity aeromagnetic survey was conducted by Questor Surveys Limited (collected $216000 \mathrm{~km}$ magnetic data). Data were collected using a helium vapor magnetometer with a sensitivity of $0.009 \mathrm{nT}$ mounted in a tail stinger. Quality control provided by Bischke through International Exploration. Data quality was excellent, with average noise in the $0.01-0.02 \mathrm{nT}$ range and with maximum noise generally not exceeding $0.15 \mathrm{nT}$ (Bischke et al. 1990). Datum level from Hsu et al. (2004) was used as a reference to adjust all of the other datasets shown in Fig. 1. The mean errors and standard deviations relative to Hsu et al. (2004) are -22.25 and $38.49 \mathrm{nT}$ for CCOP (1996), -14.39 and $37.83 \mathrm{nT}$ for Quesnel et al. (2009) dataset, and 3.13 and $33.68 \mathrm{nT}$ for the Philippine area (1983) (Fig. 4). After datum adjustment and filtering using the GMT software (Wessel and Smith 1998) (20 points moving average, weights are given by the Gaussian function), the newly compiled magnetic anomaly map of the East Asian was generated and shown in Fig. 5.

IGRF is a mathematical and theoretical modeling of the Earth's main magnetic field. Removing the observed magnetic field from the IGRF, we can only obtain the general magnetic anomaly. Several secondary effects may also contribute to the magnetic anomaly, such as different crustal or lithospheric materials, oceanic currents, diurnal variations and so on. However, the effects caused by oceanic currents, the magnetic fields predicted by both models (ECCO and OCCAM) have an amplitude range of $2 \mathrm{nT}$ at the satellite altitude (430 km) (Manoj et al. 2006). Compared to the crustal magnetic field ( $20 \mathrm{nT}$ at the altitude of $400 \mathrm{~km}$ ), the contribution from ocean circulation is small. Of course, at sea level the instrument can collect higher strength magnetic field. The temporal variation for the strength of the magnetic field radial component induced by the Kuroshio Current is $-7 \sim 4 \mathrm{nT}$ at the ocean surface (Singh et al. 2009). These values are close to the background values of magnetic anomalies collected at sea level. Although ocean current motional induction can produce quasi-static long-wavelength anomalies (Vivier et al. 2004), the main contributors to the long wavelength anomalies are induced $\left(\mathrm{M}_{\mathrm{i}}\right)$ and remnant $\left(\mathrm{M}_{\mathrm{r}}\right)$ magnetization in the Earth's crust. The Earth's main magnetic anomaly is the inducing magnetic field due to the induced magnetization of lithospheric materials. In addition, we applied cross-over error analysis (Hsu 1995) to adjust datum level and reduce the seasonal effects and short-wavelength (minor effects) signals. 


\section{NEW MAGNETIC MAP}

This discussion will focus on the characteristics of magnetic anomalies in areas of high data density in the northernmost SCS margin, northwestern part of the WPB and East China Sea basins (Fig. 1).

\subsection{NE-SW Trending High Magnetic Anomaly Zone in the Northern SCS}

New magnetic anomalies on the northern SCS conti- nental shelf show NE-SW trend high positive amplitude magnetic anomaly from southwest Taiwan to longitude $114.5^{\circ} \mathrm{E}$, which reflect the rifted Chinese continental margin (Chang 1992; Yu 1994; Yeh 2006) or the relict arcs and back arc basins (Sibuet and Hsu 1997). Several previous studies (Hsu et al. 1998, 2004; Li et al. 2008a, b, 2010) also mentioned this NE-SW trending high magnetic zone. In Fig. 5 this high magnetic zone is prominent but becomes less continuous southwest of the Penghu islands. This was probably related to low susceptibility materials [thick sediments in Tainan Basin (TNB)] or the rifting phase of the
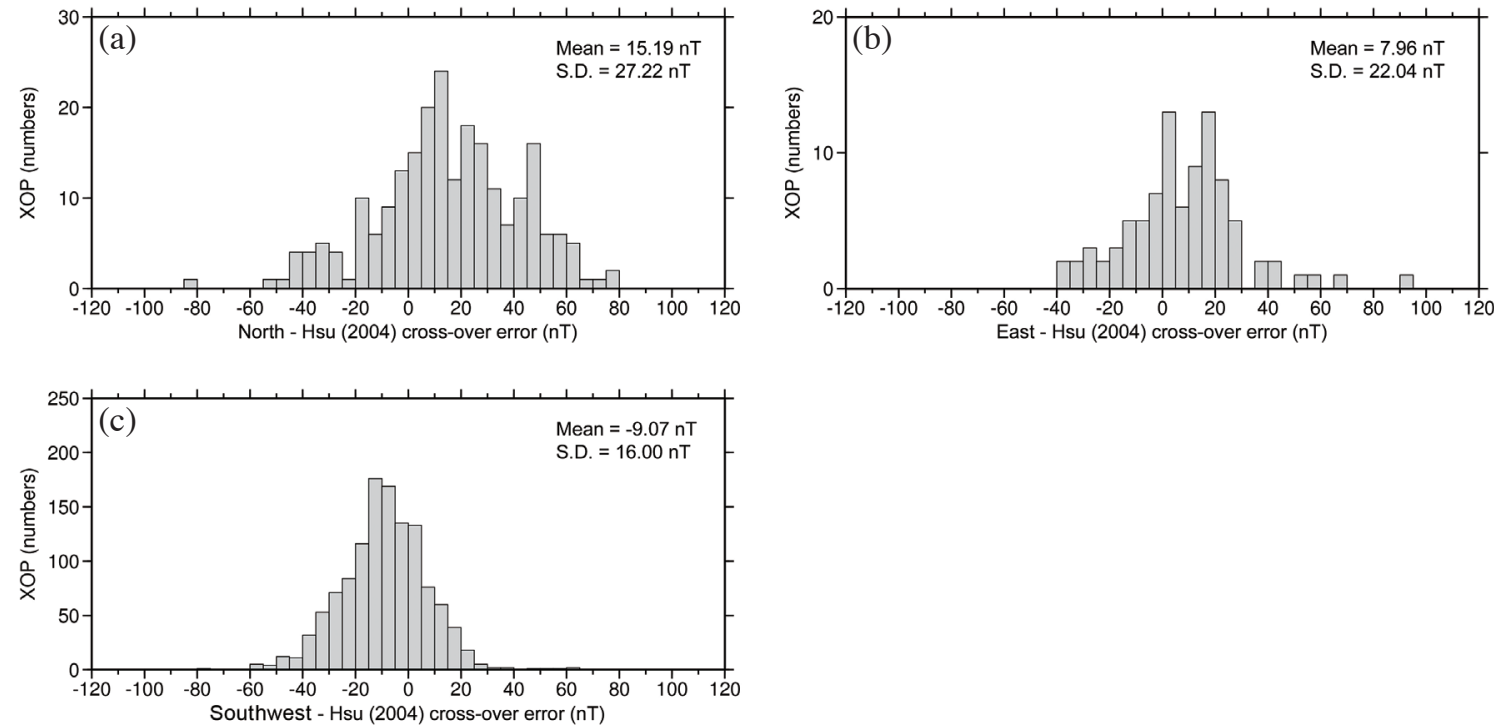

Fig. 3. (a) Cross-over errors between new collected data (north part) and Hsu et al. (2004) dataset. (b) Cross-over errors between new collected data (east part) and Hsu et al. (2004) dataset. (c) Cross-over errors between new collected data (southwest part) and Hsu et al. (2004) dataset.
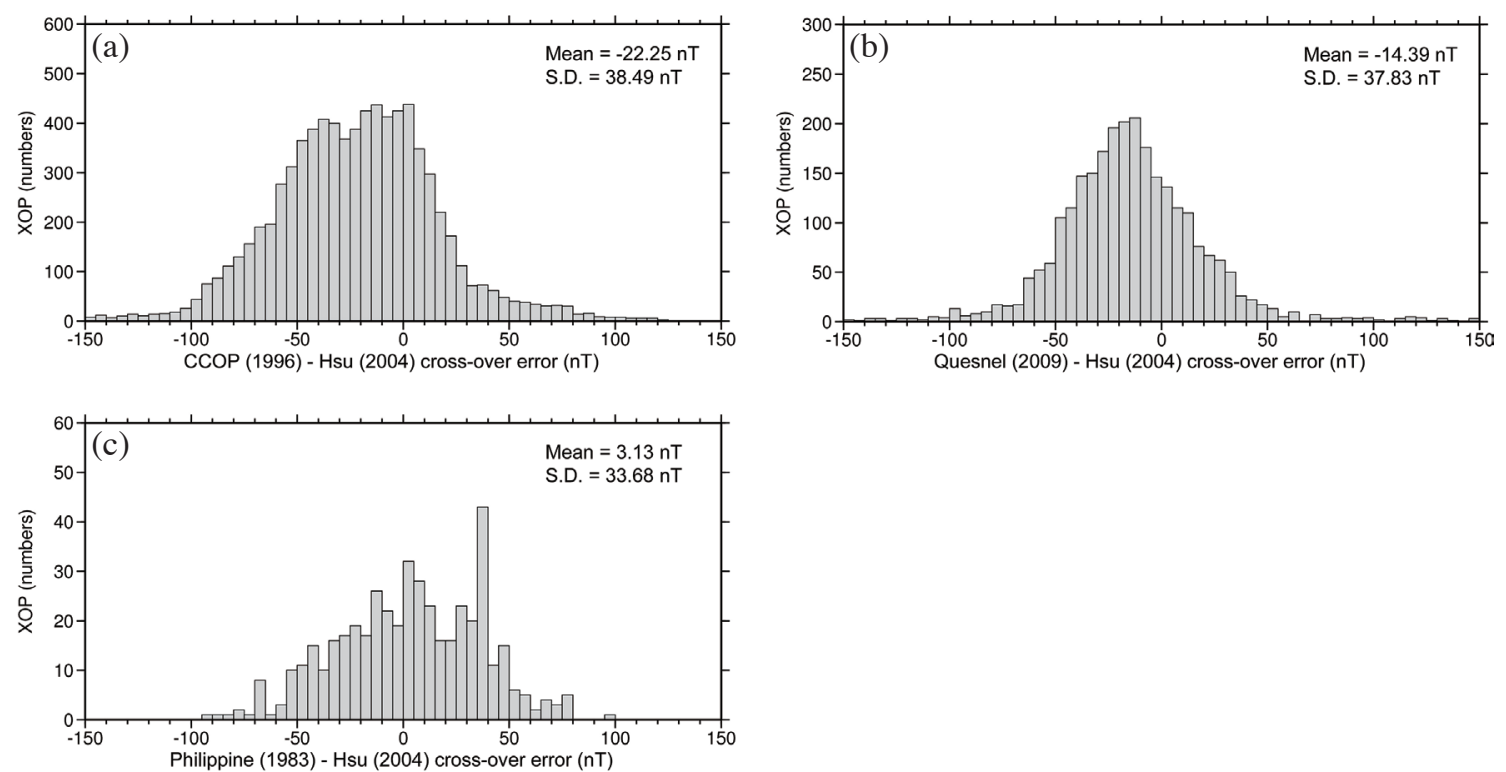

Fig. 4. (a) Cross-over errors between CCOP (1996) dataset and Hsu et al. (2004) dataset. (b) Cross-over errors between Quesnel et al. (2009) dataset and Hsu et al. (2004) dataset. (c) Cross-over errors between Philippine (Bureau of Energy Development 1985) dataset and Hsu et al. (2004) dataset. 


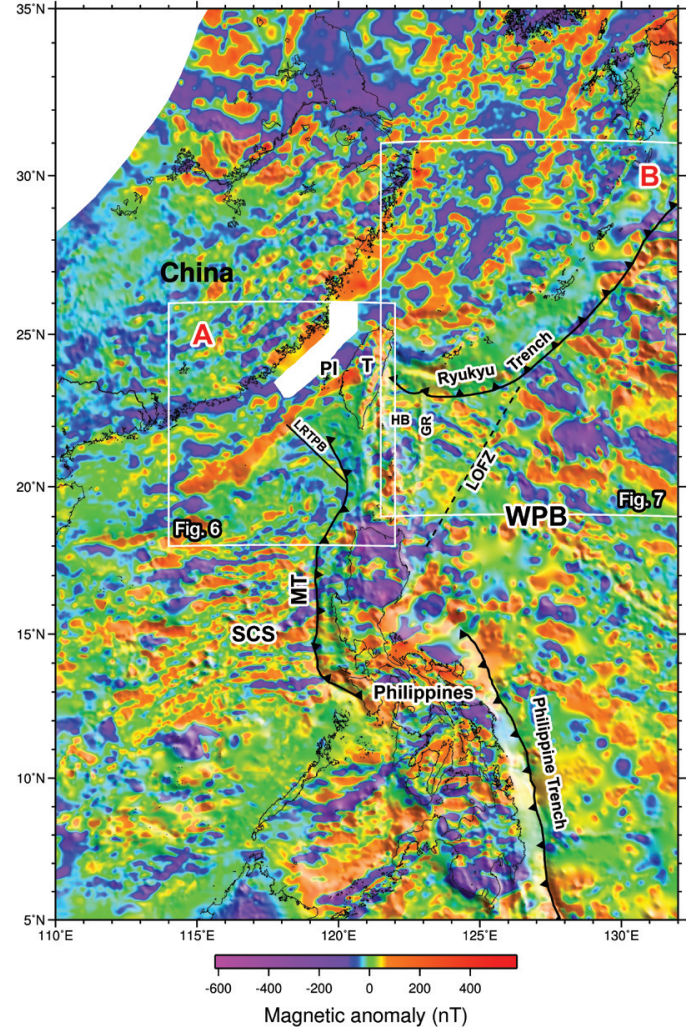

Fig. 5. New magnetic anomaly map of East Asia. GR: Gagua Ridge; HB: Huatung Basin; MT: Manila Trench; PI: Penghu islands; SCS: South China Sea; T: Taiwan; WPB: West Philippine Basin; LOFZ: Luzon-Okinawa fracture zone.

TNB (Yeh 2006). The LRTPB [Luzon-Ryukyu Transform Plate Boundary (Hsu et al. 2004)] shows a prominent contrast in the magnetic anomaly pattern. Several prominent ENE-WSW trending magnetic lineations are observed south of the LRTPB; to the north of the LRTPB, a weak variation in the magnetic anomaly amplitude is displayed. Morphologically, the high magnetic anomaly zone is NE-SW parallel to the trending of the northern SCS margin. However, to northeast LRTPB the linear high magnetic zone is shifted further north and the trend of the continental slope changes from one side to the other side of the LRTPB. This phenomenon may imply different tectonic characteristics in this high magnetic anomaly zone on each side of the LRTPB.

Across the northern SCS margin, several ESPs (expanding spread profiles), OBS (ocean bottom seismograph), and multi-channel seismic survey results indicate that voluminous syn- or post-rift magma intrusions into the upper crust had occurred in the continental-oceanic transitional zone (Nissen et al. 1995; Yan et al. 2001; Tsai et al. 2004; Wang et al. 2006). A high velocity layer with an average thickness of $4 \mathrm{~km}$ was found in the base of the lower crust over the shelf and slope. Yan et al. (2006) proposed that volcanism during contemporaneous rifting and seafloor spreading in the SCS was very weak in the margins and adjacent areas.
They also concluded that the margins of the northern SCS belong to the non-volcanic type. Russell and Whitmarsh (2003) noted that even in the non-volcanic rifted margin, there are obvious intrusive bodies within the serpentinized zone of exhumed sub-continental mantle. It has long been suggested that a Mesozoic subduction zone existed along the offshore coastal region of Southern China (Jahn et al. 1976; Gilder et al. 1996; Lapierre et al. 1997; Chen and Jahn 1998; Zhou and Li 2000). The serpentinized mantle wedge could also be a possible reason for the high magnetic anomaly as in the case of the Cascadian margin (Blakely et al. 2005).

The east coast of the U.S.A. is a classic passive margin. The boundary between the transitional crust and the oceanic crust is marked by the linear East Coast magnetic anomaly (ECMA) (Sheridan 1987; Holbrook and Kelemen 1993; Talwani et al. 1995; Behn and Lin 2000). Several proposed models explaining its origin and history incorporate volcanic seaward-dipping reflectors (Hinz 1981; Holbrook and Kelemen 1993), a mafic intrusive basement (Keller et al. 1954), and an edge effect (Keen 1969; Emery et al. 1970) caused by close-proximity differences in magnetic properties. Geological features in the northern SCS continental margin are similar to the east coast of the U.S.A.. This mechanism may be similar. However, the formation models for these two significant features are still controversial. By combining detailed magnetic, gravity, seismic information, the crustal structure, and magnetic properties, the formation mechanism of the high magnetic anomaly zone in the northern SCS can be better understood.

\subsection{New Magnetic Lineation Pattern in the Northwestern Part of the WPB}

In a previous study, Hilde and Lee (1984) suggested that the WPB was formed between 58 - 33 Ma by two spreading phases according to magnetic data and seafloor structure analyses. In their model the first spreading phase between 58 - 45 Ma was in a NE-SW direction at a halfspreading rate of $44 \mathrm{~mm} \mathrm{yr}^{-1}$. The second spreading phase was between $45-33 \mathrm{Ma}$ in a N-S direction, with the spreading rate slowed down to $18 \mathrm{~mm} \mathrm{yr}^{-1}$. They identified magnetic lineations $\mathrm{C} 17$ - $\mathrm{C} 22$ between the GR and the LOFZ (including $\mathrm{E}-\mathrm{W}$ and NW-SE trending magnetic lineations) and C16 - C19 in Huatung Basin (E-W trending magnetic lineations). However, in their study the data density was poor in the northwestern corner of the WPB. Hsu et al. (1996), proposed that the spreading fabrics between the LOFZ, the GR and the Ryukyu Trench are in favor of the first spreading stage (NE-SW trending) based on the swath bathymetric data. In our new magnetic anomaly dataset we improved the data density especially between the GR and the LOFZ (Fig. 1). In Fig. 5 the NW-SE direction of the magnetic lineations is obvious between the LOFZ and the GR. This indicates that the spreading direction is NE-SW in this area. 
The detailed bathymetric data also shows NW-SE trending spreading fabrics and several NE-SW trending fracture zones (Yeh et al. 2013). Both magnetic and bathymetric data show that the spreading direction is NE-SW in this area. It implies that the age of the oceanic crust formation in this area is similar to the early stage of the WPB. In the Huatung Basin the magnetic lineations display an E-W direction as presented in the previous study (Hsu et al. 1998). The different spreading direction on both sides of the GR could imply different periods in time.

\section{EQUIVALENT MAGNETIZATION AND TECTONIC INTERPRETATIONS}

To understand the geomagnetic characteristics of East Asia we conducted a magnetization inversion using new compiled magnetic data. Taking into account the geomagnetic inclination and declination we selected two areas (A and B in Fig. 5) for the magnetization inversion. A grid spacing of $6 \times 6 \mathrm{~km}$ was adopted for the magnetic anomalies. The equivalent magnetization of each block was obtained by inverting the magnetic data using the least-square method (Menke 1984). The bathymetric data from the Global Sea Floor Topography of Smith and Sandwell (1997) were used to reduce the topographic effect. The corresponding bathymetry was gridded at the same spacing as the magnetic data. Furthermore, we assumed that the magnetic anomalies are attributed to an equivalent layer of constant $6 \mathrm{~km}$ thickness and the top of each block is the seafloor. The inversion calculation was accomplished using the LSQR algorithm (Paige and Saunders 1982). The magnetization direction was presumed to be the same as the present-day geomagnetic field (inclination is set to $31.64^{\circ}$ and the declination to $-2.72^{\circ}$ based on the IGRF11 model) in area A (Fig. 6) and $\left(\mathrm{I}=34.02^{\circ}, \mathrm{D}=-4.01^{\circ}\right)$ in area $\mathrm{B}$ (Fig. 7).

\subsection{Northern South China Sea and Western Taiwan}

As shown in Fig. 6 an apparent broad highly magnetized NE-SW zone is trending parallel to the SCS margin. This high magnetization zone from the west Taiwan region [Lukang Magnetization High (LMH)] (Hsu et al. 2008) extends to about $114^{\circ} \mathrm{E}$, but becomes lower close to the Penghu islands. Compared with the magnetic anomaly pattern (Fig. 5), this highly magnetized zone reveals a small north shift and seems to consist of double belts between $114-118.5^{\circ} \mathrm{E}$. Hsu et al. (2008) suggested that the high magnetization in the LMH is related to deep-seated intrusive rocks of intermediate to mafic composition in the crustal level. Between $114-118.5^{\circ} \mathrm{E}$, the high magnetization zone should be associated with a high magnetic anomaly zone. The possible source is still controversial. We suggest that the source of this high magnetization zone may differ from the LMH.

Between the Luzon Arc and the Manila Trench a low magnetization zone extends into South Taiwan Island up to south of the LMH. Compared with the oceanic crust and volcanic arc, this area contains more complex materials and thick sediments. The other low magnetization zone is located south of the high magnetization belt of the northern SCS, roughly bordering the west side of the continental-oceanic boundary identified by Hsu et al. (2004) (black dashed line in Fig. 6). TNB and Chaoshan Depression (CD) are located

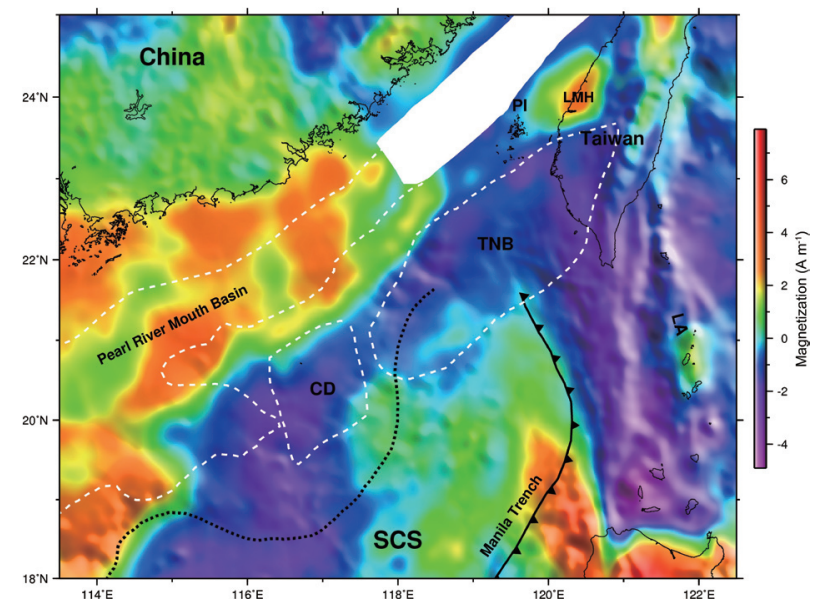

Fig. 6. Equivalent magnetization distribution for the magnetic data shown in Fig. 5 area A. CD: Chaoshan Depression; LA: Luzon Arc; LMH: Lukang Magnetization High; PI: Penghu islands; SCS: South China Sea; TNB: Tainan Basin. Black dashed lines indicate COB (continental-oceanic boundary) suggested by Yeh and Hsu (2004).

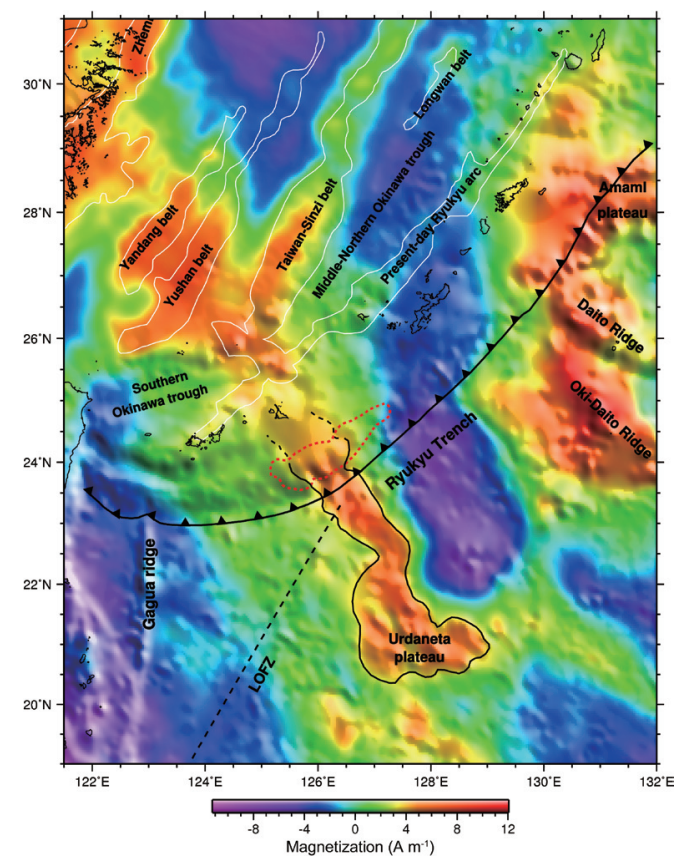

Fig. 7. Equivalent magnetization distribution for the magnetic data shown in Fig. 5 area B. Red dashed line indicates high gravity area identified from Hsu et al. (1996); white lines indicate belts identified from Hsu et al. (2001). LOFZ: Luzon-Okinawa fracture zone; T: Taiwan. 
in this low magnetization zone. In contrast, most of the Pearl River Mouth Basin (PRMB) reveals high magnetization. Sedimentary basins generally contain thick low susceptibility sediments. The different magnetization features between PRMB, TNB, and CD could be related to deeper structures.

\subsection{East China Sea and Northwestern Part of the WPB}

In the East China Sea the magnetic high trend is roughly parallel to the Mainland China shoreline on the west side of the Taiwan-Sinzi belt (Fig. 5). Sibuet and Hsu (1997) interpreted these belts of basins and ridges as relict back-arc basins and remnant portions of volcanic arcs of the current Ryukyu subduction system. The resulting magnetizations roughly coincide with the Yandang, Yushan, Taiwan-Sinzi belts and present-day Ryukyu arc (Fig. 7). Between Mainland China and the Taiwan-Sinzi belt, the belts are parallel along a NE-SW trend. The trend changes east of the Taiwan-Sinzi belt. The trend of the belts and the Ryukyu island arc are parallel to the Ryukyu trench. Between the Ryukyu arc and the Ryukyu Trench, Hsu et al. (1996) identified a peculiar fore arc feature about $250 \mathrm{~km}$ long, located near $24.5^{\circ} \mathrm{N}, 126^{\circ} \mathrm{E}$. It displays a strong positive gravity anomaly (red dashed line area in Fig. 7). They suggested that this stable feature, named the Gagua terrain, could be a part of the former Gagua ridge or possibly part of the former Luzon arc. In Fig. 7, the magnetic inversion result does not reveal an isolated pattern but instead a continuous high magnetization zone that extends southeastward to the Urdaneta Plateau. Based on the magnetic inversion result we suggest that this continuous high magnetization zone is related to the Urdaneta Plateau. Subduction of the plateau (or fracture zone in this area) could cause the topography uplift in the fore arc area resulting on the high free-air gravity anomaly. Hsu et al. (2013) through deep multi-channel seismic reflection profile analysis proposed that the elongated distribution of the inner wedge spatially coincides with the high free-air gravity anomaly. Therefore, the gravity high is related to the doming of the inner wedge.

In the WPB the trend of the most high magnetization zones is roughly perpendicular to the trench (Fig. 7). In the southwestern part of the Ryukyu Trench the high magnetization zone cut across the Ryukyu Trench. At about $126^{\circ} \mathrm{E}$, the Ryukyu Trench changes its trend, gradually from NE-SW to E-W. But this high magnetization zone still follows the plate motion direction. In the northeastern part of the Ryukyu Trench the high magnetization roughly follows the oceanic ridges (Daito and Oki-Daito ridge) and plateau (Amami plateau) distribution. The high magnetization zone also cuts across the Ryukyu Trench. This may indicate that some parts of the ridges are already subducted beneath the Ryukyu trench. Between the GR and LOFZ, the high magnetization trend also reveals a NW-SE direction which is consistent with the magnetic anomaly pattern.

\section{CONCLUSION}

We constructed a new magnetic map of the East Asian region using land, shipboard and aeromagnetic data. The new magnetic dataset can be used to work on both fundamental and applied researches; especially on the specific questions linked to the structure or tectonics of East Asia. Based on this new magnetic anomaly map of East Asia and further analysis we obtained some basic tectonic insights. The main points from the newly compiled magnetic data of East Asia are:

(1) We confirmed the existence of several E-W trending magnetic lineations (C15 - C17) which were identified by Hsu et al. (2004). A NE-SW trending magnetic anomaly high from southwestern Taiwan to the offshore South China continental margin was observed; however, it appears to be less continuous southwest of the Penghu islands. The relative magnetization map shows that the north SCS margin contains a broad high magnetization zone and high magnetization was located at southwest Taiwan (LMH). A significant feature, the PRMB is associated with high magnetization, but the Tainan Basin and $\mathrm{CD}$ are located in a low magnetization zone.

(2) Between the Gagua Ridge and the LOFZ the NW-SE trending magnetic lineations indicates a NE-SW spreading direction. This direction implies that the age of the oceanic crust in this area is similar to the first spreading stage of the WPB (Hilde and Lee 1984).

(3) Based on the equivalent magnetization distribution between Mainland China and the Ryukyu Trench, the continental rifting of the East China Sea shelf basin has produced several rifted ridges and basins. The magnetic inversion results show that the belts are parallel and trending about $\mathrm{N} 075^{\circ}$ and at the eastern side of the Taiwan-Sinzi belt the trend is parallel to the Ryukyu Trench. In the WPB some high magnetization zones are subducted beneath the Ryukyu fore arc (Urdaneta and Amami plateau) implying that highly magnetized materials exist in the subducted Philippine Sea Plate.

Acknowledgements Constructive reviews from Dr. Wu., F. T. and one Anonymous Reviewer are appreciated. This research was mainly supported by the Ministry of the Interior, Republic of China and the Ministry of Science and Technology of Taiwan.

\section{REFERENCE}

Behn, M. D. and J. Lin, 2000: Segmentation in gravity and magnetic anomalies along the U.S. East Coast passive margin: Implications for incipient structure of the oceanic lithosphere. J. Geophys. Res., 105, 25769-25790, doi: 10.1029/2000JB900292. [Link]

Bischke, R. E., J. Suppe, and R. del Pilar, 1990: A new 
branch of the Philippine fault system as observed from aeromagnetic and seismic data. Tectonophysics, 183, 243-264, doi: 10.1016/0040-1951(90)90419-9. [Link]

Blakely, R. J., T. M. Brocher, and R. E. Wells, 2005: Subduction-zone magnetic anomalies and implications for hydrated forearc mantle. Geology, 33, 445-448, doi: 10.1130/G21447.1. [Link]

Bureau of Energy Development, 1985: High-sensitivity aeromagnetic survey, magnetic color map, Scale, 1:250,000, Bur. Energy Dev., Minist. Energy, Manila, 37 sheets.

Chandler, M. T. and P. Wessel, 2008: Improving the quality of marine geophysical track line data: Alongtrack analysis. J. Geophys. Res., 113, B02102, doi: 10.1029/2007JB005051. [Link]

Chang, M. D., 1992: Integrated geological and geophysical interpretation of the Penghu sedimentary Basin. Petrol. Geol. Taiwan, 27, 237-250.

Chang, Y. C., C. H. Tsai, and S. K. Hsu, 2011: Generalized XYZ data editor software for marine geophysical survey. J.Mar. Sci.Technol., 19, 1-5.

Chen, J. and B. Jahn, 1998: Crustal evolution of southeastern China: $\mathrm{Nd}$ and $\mathrm{Sr}$ isotopic evidence. Tectonophysics, 284, 101-133, doi: 10.1016/S0040-1951(97)00186-8. [Link]

Emery, K. O., E. Uchupi, J. D. Phillips, C. O. Bowin, E. T. Bunce, and S. T. Knott, 1970: Continental rise off eastern North America. AAPG Bull., 54, 44-108.

Finlay, C. C., S. Maus, C. D. Beggan, T. N. Bondar, A. Chambodut, T. A. Chernova, A. Chulliat, V. P. Golovkov, B. Hamilton, M. Hamoudi, R. Holme, G. Hulot, W Kuang, B. Langlais, V. Lesur, F. J. Lowes, H. Lühr, S. Macmillan, M. Mandea, S. McLean, C. Manoj, M. Menvielle, I. Michaelis, N. Olsen, J. Rauberg, M. Rother, T. J. Sabaka, A. Tangborn, L. Tøffner-Clausen, E. Thébault, A. W. P. Thomson, I. Wardinski, Z. Wei, and T. I. Zvereva, 2010: International Geomagnetic Reference Field: The eleventh generation. Geophys. J. Int., 183, 1216-1230, doi: 10.1111/j.1365-246X.2010.04804.x. [Link]

Geological Survey of Japan and Coordinating for Coastal and Offshore Geoscience Programs in East and Southeast Asia (CCOP), 1996: Magnetic anomaly map of East Asia 1:4,000,000 CD-ROM, Digital Geoscience Map 2 (P-1).

Gilder, S. A., J. Gill, R. S. Coe, X. Zhao, Z. Liu, G. Wang, K. Yuan, W. Liu, G. Kuang, and H. Wu, 1996: Isotopic and paleomagnetic constraints on the Mesozoic tectonic evolution of south China. J. Geophys. Res., 101, 16137-16154, doi: 10.1029/96JB00662. [Link]

Hilde, T. W. C. and C. S. Lee, 1984: Origin and evolution of the West Philippine Basin: A new interpretation. Tectonophysics, 102, 85-104, doi: 10.1016/0040-1951(84)90009-X. [Link]
Hinz, K., 1981: A hypothesis on terrestrial catastrophes: Wedges of very thick ocean-ward dipping layers beneath passive continental margins - Their origin and paleoenvironmental significance. Geol. Jahrbuch Reihe E. Geophys., 22, 3-28.

Holbrook, W. S. and P. B. Kelemen,1993: Large igneous province on the US Atlantic margin and implications for magmatism during continental breakup. Nature, 364, 433-436, doi: 10.1038/364433a0. [Link]

Hsu, S. K., 1995: XCORR: A cross-over technique to adjust track data. Comput. Geosci., 21, 259-271, doi: 10.1016/0098-3004(94)00070-B. [Link]

Hsu, S. K., J. C. Sibuet, S. Monti, C. T. Shyu, and C. S. Liu, 1996: Transition between the Okinawa trough backarc extension and the Taiwan collision: New insights on the southernmost Ryukyu subduction zone. Mar. Geophys. Res., 18, 163-187, doi: 10.1007/BF00286076. [Link]

Hsu, S. K., C. S. Liu, C. T. Shyu, S. Y. Liu, J. C. Sibuet, S. Lallemand, C. S. Wang, and D. Reed, 1998: New gravity and magnetic anomaly maps in the Taiwan-Luzon region and their preliminary interpretation. Terr. Atmos. Ocean. Sci., 9, 509-532.

Hsu, S. K., J. C. Sibuet, and C. T. Shyu, 2001: Magnetic inversion in the East China Sea and Okinawa Trough: Tectonic implications. Tectonophysics, 333, 111-122, doi: 10.1016/S0040-1951(00)00270-5. [Link]

Hsu, S. K., Y. Yeh, W. B. Doo, and C. H. Tsai, 2004: New bathymetry and magnetic lineations identifications in the northernmost South China Sea and their tectonic implications. Mar. Geophys. Res., 25, 29-44, doi: 10.1007/s11001-005-0731-7. [Link]

Hsu, S. K., Y. C. Yeh, C. L. Lo, A. T. Lin, and W. B. Doo, 2008: Link between crustal magnetization and earthquakes in Taiwan. Terr. Atmos. Ocean. Sci., 19, 445450, doi: 10.3319/TAO.2008.19.5.445(T). [Link]

Hsu, S. K., Y. C. Yeh, J. C. Sibuet, W. B. Doo, and C. H. Tsai, 2013: A mega-splay fault system and tsunami hazard in the southern Ryukyu subduction zone. Earth Planet. Sci. Lett., 362, 99-107, doi: 10.1016/j. eps1.2012.11.053. [Link]

Jahn, B. M., P. Y. Chen, and T. P. Yen, 1976: Rb-Sr ages of granitic rocks in southeastern China and their tectonic significance. Geol. Soc. Am. Bull., 86, 763-776, doi: 1 0.1130/0016-7606(1976)87<763:RAOGRI>2.0.CO;2. [Link]

Keen, M. J., 1969: Possible Edge Effect to explain Magnetic Anomalies off the Eastern Seaboard of the US. Nature, 222, 72-74, doi: 10.1038/222072a0. [Link]

Keller, F. Jr., J. L. Meuschke, and L. R. Alldredge, 1954: Aeromagnetic surveys in the Aleutian, Marshall, and Bermuda islands. Eos, Trans., AGU, 35, 558-572.

Lapierre, H., B. M. Jahn, J. Charvet, and Y. W. Yu, 1997: Mesozoic felsic arc magmatism and continental olivine tholeiites in Zhejiang Province and their relationship 
with the tectonic activity in southeastern China. Tectonophysics, 274, 321-338, doi: 10.1016/S0040-1951(97)00009-7. [Link]

Li, C. F., Z. Zhou, H. Hao, H. Chen, J. Wang, B. Chen, and $\mathrm{J} . \mathrm{Wu}, 2008 \mathrm{a}$ : Late Mesozoic tectonic structure and evolution along the present-day northeastern South China Sea continental margin. J. Asian Earth Sci., 31, 546-561, doi: 10.1016/j.jseaes.2007.09.004. [Link]

Li, C. F., Z. Zhou, J. Li, B. Chen, and J. Geng, 2008b: Magnetic zoning and seismic structure of the South China Sea ocean basin. Mar. Geophys. Res., 29, 223-238, doi: 10.1007/s11001-008-9059-4. [Link]

Li, C. F., X. Shi, Z. Zhou, J. Li, J. Geng, and B. Chen, 2010: Depths to the magnetic layer bottom in the South China Sea area and their tectonic implications. Geophys. J. Int., 182, 1229-1247, doi: 10.1111/j.1365-246X.2010.04702.x. [Link]

Manoj, C., A. Kuvshinov, S. Maus, and H. Lühr, 2006: Ocean circulation generated magnetic signals. Earth Planets Space, 58, 429-437.

Menke, W., 1984: Geophysical Data Analysis: Discrete Inverse Theory, Academic Press, London, $260 \mathrm{pp}$.

Metzger, D. and J. Campagnoli, 2007: Marine Trackline Geophysics Data on DVD, version 5.0.10, Natl. Geophys. Data Cent., Boulder, Colo.

Nissen, S. S., D. E. Hayes, P. Buhl, J. Diebold, B. Yao, W. Zeng, and Y. Chen, 1995: Deep penetration seismic soundings across the Northern margin of the South China Sea. J. Geophys. Res., 100, 22407-22433, doi: 10.1029/95JB01866. [Link]

Paige, C. C. and M. A. Saunders, 1982: LSQR: An algorithm for sparse linear equations and sparse least squares. ACM T. Math. Software, 8, 43-71, doi: 10.1145/355984.355989. [Link]

Quesnel, Y., M. Catalán, and T. Ishihara, 2009: A new global marine magnetic anomaly data set.J.Geophys. Res., 114, B04106, doi: 10.1029/2008JB006144. [Link]

Russell, S. M. and R. B. Whitmarsh, 2003: Magmatism at the west Iberia non-volcanic rifted continental margin: Evidence from analyses of magnetic anomalies. Geophys. J. Int., 154, 706-730, doi: 10.1046/j.1365-246X.2003.01999.x. [Link]

Sheridan, R. E., 1987: The Passive Margin of the U.S.A.. EPISODES, 10, 254-258.

Sibuet, J. C. and S. K. Hsu, 1997: Geodynamics of the Taiwan arc-arc collision. Tectonophysics, 274, 221-251, doi: 10.1016/S0040-1951(96)00305-8. [Link]

Singh, K. H., W. Kuang, T. J. Sabaka, and A. V. Kuvshinov, 2009: Oceanic Magnetic Anomalies Induced from Kuroshio Currents, American Geophysical Union, Fall Meeting 2009, abstract \#GP33A-0738.

Smith, W. H. F. and D. T. Sandwell, 1997: Global sea floor topography from satellite altimetry and ship depth soundings. Science, 277, 1956-1962, doi: 10.1126/ science.277.5334.1956. [Link]

Talwani, M., J. Ewing, R. E. Sheridan, W. S. Holbrook, and L. Glover III, 1995: The edge experiment and the U.S. East Coast Magnetic Anomaly. In: Banda, E., M. Torné, and M. Talwani (Eds.), Rifted Ocean-Continent Boundaries, NATO ASI Series, Vol. 463, Springer Netherlands, 155-181, doi: 10.1007/978-94-011-00434_9. [Link]

Tsai, C. H., S. K. Hsu, Y. C. Yeh, C. S. Lee, and K. Y. Xia, 2004: Crustal thinning of the northern continental margin of the South China Sea. Mar. Geophys. Res., 25, 63-78, doi: 10.1007/s11001-005-0733-5. [Link]

Vivier, F., E. Maier-Reimer, and R. H. Tyler, 2004: Simulations of magnetic fields generated by the Antarctic Circumpolar Current at satellite altitude: Can geomagnetic measurements be used to monitor the flow? Geophys. Res. Lett., 31, L10306, doi: 10.1029/2004GL019804. [Link]

Wang, T. K., M. K. Chen, C. S. Lee, and K. Xia, 2006: Seismic imaging of the transitional crust across the northeastern margin of the South China Sea. Tectonophysics, 412, 237-254, doi: 10.1016/j.tecto.2005.10.039. [Link]

Wessel, P. and W. H. F. Smith, 1998: New, improved version of generic mapping tools released. Eos, Trans., $A G U, 79,579$, doi: 10.1029/98EO00426. [Link]

Yan, P., D. Zhou, and Z. Liu, 2001: A crustal structure profile across the northern continental margin of the South China Sea. Tectonophysics, 338, 1-21, doi: 10.1016/ S0040-1951(01)00062-2. [Link]

Yan, P., H. Deng, H. Liu, Z. Zhang, and Y. Jiang, 2006: The temporal and spatial distribution of volcanism in the South China Sea region. J. Asian Earth Sci., 27, 647659, doi: 10.1016/j.jseaes.2005.06.005. [Link]

Yeh, Y. C., 2006: Tectonics of the northern South China Sea. Ph.D. Thesis, National Central Univ., Chungli, Taiwan, $149 \mathrm{pp}$.

Yeh, Y. C. and S. K. Hsu, 2004: Crustal structures of the northernmost South China Sea: Seismic reflection and gravity modeling. Mar. Geophys. Res., 25, 45-61, doi: 10.1007/s11001-005-0732-6. [Link]

Yeh, Y. C., S. K. Hsu, W. B. Doo, C. H. Tsai, and C. M. Chang, 2013: The Eocene volcanic activities and seafloor features in the northwest of the West Philippine Basin, submitted to Marine Geology.

Yu, H. S., 1994: Structure, stratigraphy and basin subsidence of Tertiary basins along the Chinese southeastern continental margin. Tectonophysics, 235, 63-76, doi: 10.1016/0040-1951(94)90017-5. [Link]

Zhou, X. M. and W. X. Li, 2000: Origin of late Mesozoic igneous rocks in southeastern China: Implications for lithosphere subduction and underplating of mafic magmas. Tectonophysics, 326, 269-287, doi: 10.1016/ S0040-1951(00)00120-7. [Link] 